\title{
Optimizing Gear Micro Geometry for Minimum Transmission Error When Considering Manufacturing Deviation
}

\author{
Layue Zhao, Minggang Du, and Yang Yang
}

\begin{abstract}
Gear transmission error (TE) is the predominant source of dynamic excitation and via a complex transfer function produces noise in the powertrain system. Minimizing transmission error is crucial for reducing gear noise. In this paper, an external helical gear pair is modeled and analyzed by an experimentally validated 3D-TCA method-GATES considering manufacturing deviation. By comparing the simulation results, the profile and lead tooth micro-modifications are compared to obtain a good result in gear transmission error and contact stress. Therefore, it is a good example to show on how to get the optimal gear tooth micro-geometry for minimum transmission error.
\end{abstract}

Index Terms-Transmission error, reducing gear noise, manufacturing deviation, gear tooth micro-geometry.

\section{INTRODUCTION}

Gears are the essential components of mechanical power transmission systems because of its relatively accurate transmission ratio, high efficiency and reliability, and widely used in many applications ranging from automotive to mechanical engineering and aerospace. Nowadays, with the increasing demand for high-speed and high power density gear applications, the basic requirements of gear transmissions are not limited to resistance and reliability, the need to optimize gears for minimum noise and vibration becomes even more important. Gear transmission error (TE) is the accepted predominant source for noise in gear set and a good control parameter for minimizing noise and dynamic load. It has previously been showed that reducing transmission error can increase gear resistance and reduce gear noise levels [1]. Thus, this paper aims to study the method for minimum transmission error.

Two main methods which are currently implemented, in order to reduce the gear noise and vibration responses of the system are by means of macro-geometry and micro-geometry modifications.

Macro-geometry is defined by gear parameters, such as number of teeth, diameters, pressure angle, face width and backlash and so on. Macro-geometry modifications involve an important and expensive change of the gear pair as well as other parameters of the gear pair; they are feasible only at the first step of the design process. They cannot be changed once the design finished.

Manuscript received August 15, 2016; revised January 22, 2017.

The authors are with the National Key Lab Of Vehicular Transmission, China North Vehicle Research Institute, Beijing, China (e-mail: 15011080272@163.com, mgdu@noveri.com.cn, yangyang913@ 163.com).
Micro-modifications include the intentional removal of material from the gear teeth flanks, so that the shape is no longer a perfect involute. Such modifications compensate teeth deflections under load, and the resulting transmission error is minimized under a specific torque. Micro-geometry modifications can be applied on the profile and lead of the gear teeth. In fact, there is a third type of modification, bias, but it is not discussed in this paper.
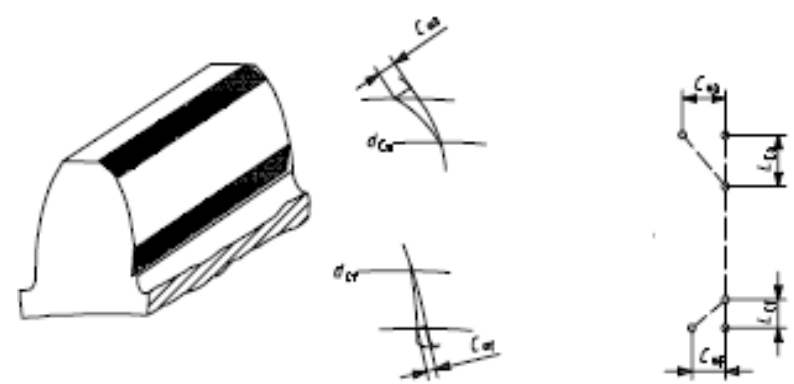

Fig. 1. Tip and root relief.
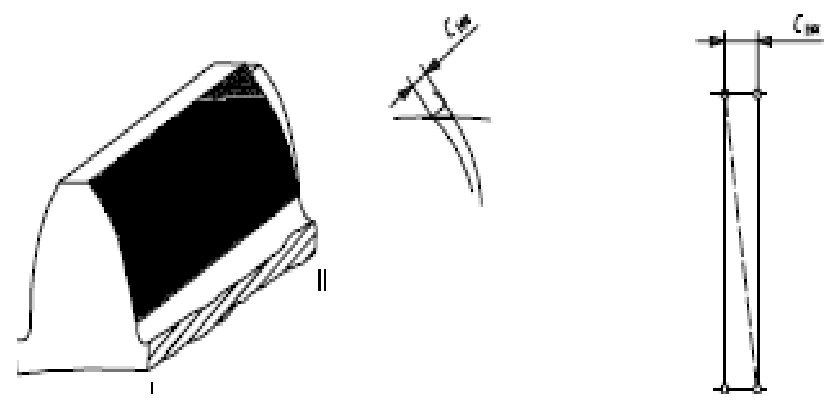

Fig. 2. Profile slope modification
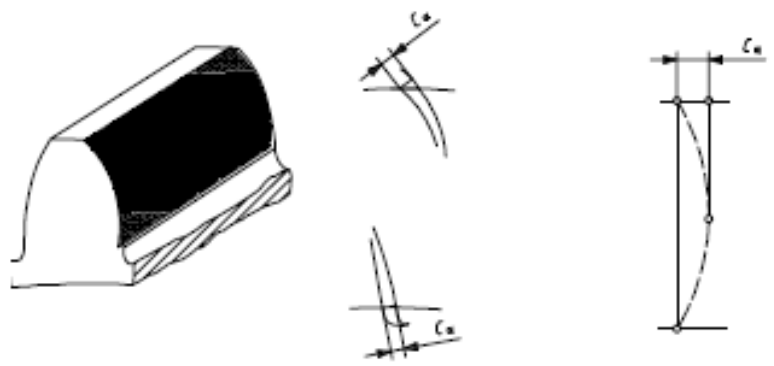

Fig. 3. Profile crowning.

For profile modifications, modification in the profile direction takes into account of tooth elastic deformation and errors due to manufacturing and assembly. Profile modifications are done for following parameters, tip and root relief, profile slope modification and profile crowning. And about lead modifications which involve applying lead slope correction and face crowning and end relief to the gears [2]. And Fig. 1 to Fig. 6 are the definition of profile and lead 
modifications.
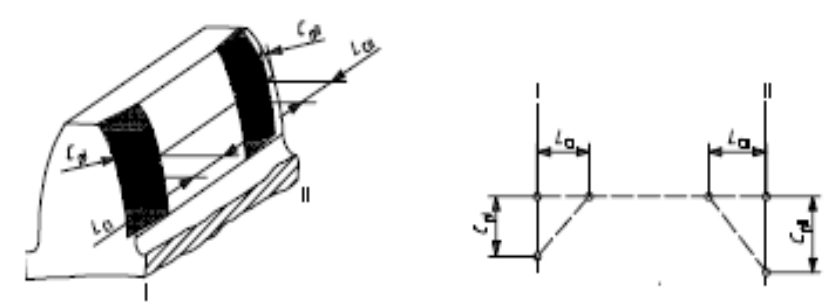

Fig. 4. End relief.

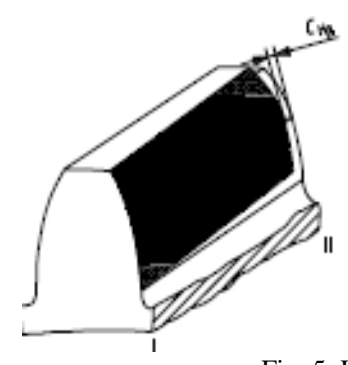

Fig. 5. Lead slope correction.
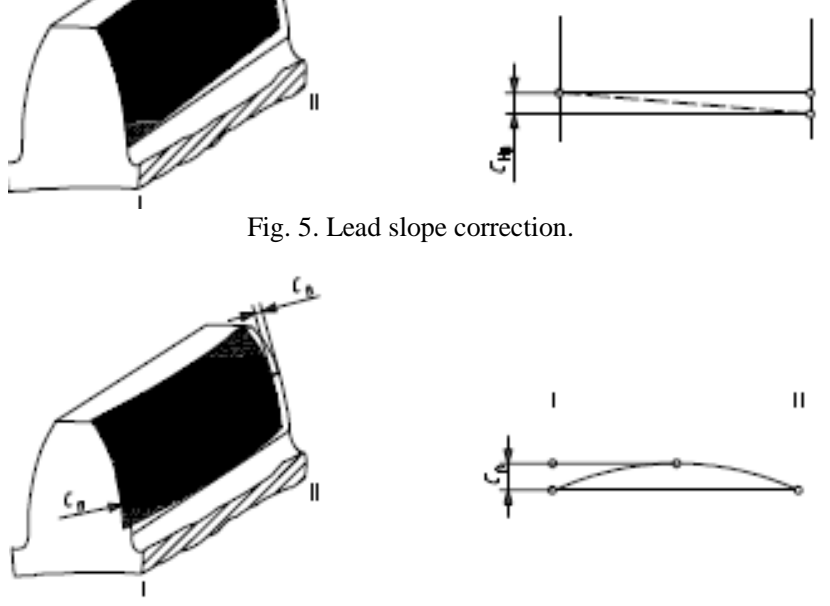

Fig. 6. Face crowning.

Transmission error research has resulted in significant noise reduction in gear systems. For example, Jiao [3] according to the gears meshing theory, considering the gear deformation, solved the static transmission error in different conditions and investigated the influence of center errors on static transmission error. Tesfahunegn [4], Velex [5] and Kissling [6] investigated the effects of the shape of tooth profile modifications on the transmission error. Frazer [7] used a validated, 3-D Finite Element Analysis (FEA) and Tooth Contact Analysis (TCA) program to optimize Gear Geometry for minimum TE. However, they didn't consider the influence of manufacturing deviation. In real gears, there will be mesh misalignment resulting from manufacturing deviations. So further research is required to optimize gear micro gemoetry for minimum transmission error when considering manufacturing deviation.

This paper will investigate the micro-geometry modifications to minimize the TE for a helical gear pair when considering manufacturing deviation. It consists of four main parts.

1. Basic calculations for mean mesh deflection and manufacturing deviation.

2. Geometry specification for the helical gear pair.

3. Results and discussions.

4. Conclusions.

\section{BASIC CALCULATIONS}

\section{A. Mean Mesh Deflection}

Mean mesh deflection [7] which was proposed by Dr. Robert Frazer (Design Unit Newcastle University) - used to estimate tip relief and also indicate how sensitive your design is to errors/misalignments.

$$
F_{r o}=\frac{F_{t}}{b C_{\gamma}}
$$

where,

$F_{t}$ : tangential force $[\mathrm{N}]$

$b$ : facewidth [mm]

$C_{\gamma}$ : combined mesh stiffness $[\mathrm{N} / \mathrm{mm} / \mathrm{um}]$-use $16-18$ as a guide value.

The mean mesh deflection is a good estimate for the amount of tip relief that should be applied to the gear profile to compensate for the elastic deflection for spur gear. For helical gears, the mean mesh deflection is better estimated by dividing this result by the $\varepsilon_{\alpha}$ (transverse contact ratio).

In this paper, the mean mesh deflection was calculated and applied to the gear profile as the value of tip relief, then other amount of tip relief are applied, comparing the results to find the optimal tip relief value.

Note that in this paper, tip relief is applied to the pinion and wheel. The parabolic tip relief was chosen to avoid high contact stress at the interface and micropitting [8] on which point. The start of tip relief is at Highest Point of Single pair Tooth Contact (HPSTC) [9], which is a good balance for lower contact stress and TE.

\section{B. Manufacturing Deviation (Misalignment)}

To ensure the results are valid, manufacturing deviation will be applied to gears. Where manufacturing deviation will be determined by ISO6336-1:2006, equation (64) [10],

$$
f_{m a}=\sqrt{f_{H \beta 1}^{2}+f_{H \beta 2}^{2}}
$$

where,

$f_{H \beta 1}$ : pinion helix slope deviation.

$f_{H \beta 2}$ : wheel helix slope deviation.

The helix slope deviation can be determined by gear quality grade which is defined based on ISO1328-1:2013 [11].

In order to compensate for the manufacturing deviation (misalignment), in this paper, different amount of face crowning will be applied to gears to obtain more uniform distribution of load over the facewidth, the results are compared to find the optimal lead modification value.

\section{GEAR GEOMETRY SPECIFICATION}

\section{TABLE I: GEAR GEOMETRY}

\begin{tabular}{ccccccccc}
\hline \hline & $\begin{array}{c}\text { No. of } \\
\text { teeth } \\
(\mathrm{Z})\end{array}$ & $\begin{array}{c}\text { Module } \\
\mathrm{m}_{\mathrm{t}}(\mathrm{mm})\end{array}$ & $\begin{array}{c}\text { angle } \alpha_{\mathrm{t}} \\
\left({ }^{0}\right)\end{array}$ & $\begin{array}{c}\mathrm{b} \\
(\mathrm{mm})\end{array}$ & $\begin{array}{c}\text { angle } \\
\beta\left({ }^{0}\right)\end{array}$ & $\begin{array}{c}\text { Quality } \\
\text { grade }\end{array}$ & $\begin{array}{c}\text { Speed } \\
\mathrm{n}_{1} \\
(\mathrm{r} / \mathrm{min})\end{array}$ & $\begin{array}{c}\mathrm{T}_{1} \\
(\mathrm{Nm})\end{array}$ \\
\hline Pinion & 23 & 3.5 & 20 & 20 & 23.75 & 7 & 200 & 500 \\
\hline wheel & 33 & 3.5 & 20 & 20 & 23.75 & 7 & & \\
\hline \hline
\end{tabular}

In this paper, a helical gear pair is investigated. The geometry parameters of the gear set are summarized in Table I. Note that the face width of gears is small to minimize body elastic deformation effects on transmission error. The speed was set at a nominal $200 \mathrm{r} / \mathrm{min}$ to minimize the influence of 
dynamic factor $\mathrm{kv}$ on the results. Dynamic factor $\mathrm{kv}$ is used by ISO calculation of load capacity and related to speed, that is the lower the speed, the smaller the $\mathrm{kv}$.

\section{RESULTS AND DisCUSSIONS}

The mean mesh deflection of the gears are calculated according to Equation (1) and represented in Table II.

\begin{tabular}{cccccc}
\multicolumn{5}{c}{ TABLE II: MEAN MESH DEFLECTION OF THE GEARS } \\
\hline \hline $\begin{array}{c}\text { helical } \\
\text { gear }\end{array}$ & 12422.4 & 20 & $16-18$ & 1.513 & $20-25$ \\
\hline \hline
\end{tabular}

Manufacturing deviations are determined based on the lead slope deviations according to Equation (2) and showed in Table III.

TABLE III: MANUFACTURING DEVIATION OF THE GEARS

\begin{tabular}{|c|c|c|c|}
\hline Helical gear & $f_{H \beta I}(u m)$ & $f_{H \beta 2}(u m)$ & $f_{m a}(u m)$ \\
\hline Quality grade 7 & 11 & 11 & 15 \\
\hline
\end{tabular}

To ensure the results are valid, manufacturing deviation equal to $15 \mathrm{um}$ will be applied to gears.

Different tip relief (profile correction) and face crowning (lead correction) will be applied to gears to find the optimal micro modifications for minimum TE. Note that the appropriate tip relief and face crowning are defined by both considering of contact stress and TE. Reducing TE but increasing contact stress may increase the risk of failure by micro-pitting or macro-pitting fatigue failure modes.

The calculation of $\mathrm{TE}$ and the definition of micro modifications are implemented by an experimentally validated 3D-TCA method-GATES (Gear Analysis for Transmission Error and Stress) [12].

Firstly, the optimal face crowning is calculated using automatic optimization module of GATES to get minimum contact stress. The settings are as follows.

1) Manufacturing deviation is equal to $15 \mathrm{um}$.

2) Parabolic tip relief equal to 20um (mean mesh deflection) are applied to pinion and wheel, the start of tip relief is HSPTC.

3) The face crowning is from 0um to 20um and set up for 6 steps.

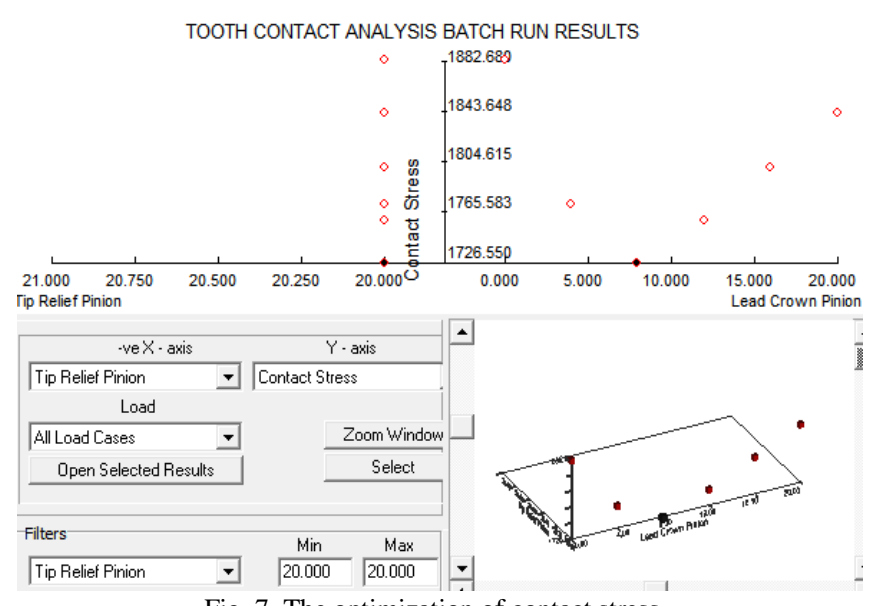

Fig. 7. The optimization of contact stress.
The optimization result of contact stress is illustrated in Fig. 7.

From Fig. 7, it can be seen that the contact stress is minimum when face crowning is equal to $8 \mathrm{um}$ which is close to the half of manufacturing deviation (15um).

The optimal value of tip relief is firstly analyzed using automatic optimization module of GATES to get minimum peak to peak TE (PPTE) with face crowning equal to $8 \mathrm{um}$. The tip relief is from 0 um to $35 \mathrm{um}$ and set up for 8 steps. The optimization result of TE is showed in Fig. 8.

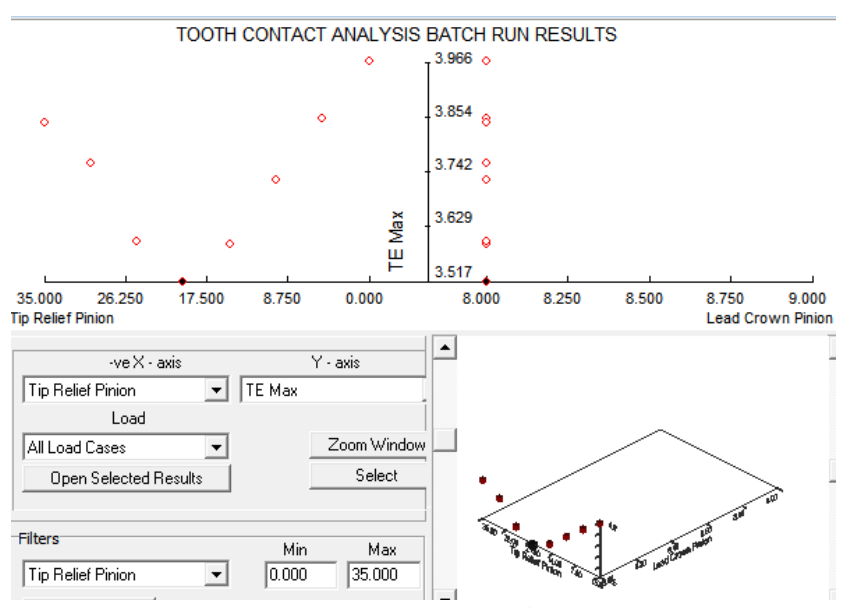

Fig. 1. The optimization of PPTE.

It can be obviously seen from Fig. 8 that the minimum PPTE is obtained when tip relief is equal to 20um which is mean mesh deflection and face crowning (8um) is close to half of manufacturing deviation (15um). The gear micro modifications are also implemented using GATES manually. The results are summarized in Table IV and Fig. 9.

\begin{tabular}{|c|c|c|}
\hline & Contact stress $(\mathrm{MPa})$ & TE(um) \\
\hline non-modification & 2531.9 & 3.894 \\
\hline tip relief 5 um $C \beta=8 u m$ & 2211.8 & 3.857 \\
\hline tip relief $10 \mathrm{um} C \beta=8 \mathrm{um}$ & 2076.8 & 3.754 \\
\hline tip relief $15 \mathrm{um} C \beta=8 \mathrm{um}$ & 1908.5 & 3.621 \\
\hline tip relief $20 \mathrm{um} C \beta=8 \mathrm{um}$ & 1720.6 & 3.58 \\
\hline tip relief $25 \mathrm{um} C \beta=8 \mathrm{um}$ & 1728.4 & 3.658 \\
\hline tip relief $30 \mathrm{um} C \beta=8 \mathrm{um}$ & 1762.9 & 3.864 \\
\hline tip relief $35 \mathrm{um} C \beta=8 \mathrm{um}$ & 1794.7 & 4.019 \\
\hline
\end{tabular}

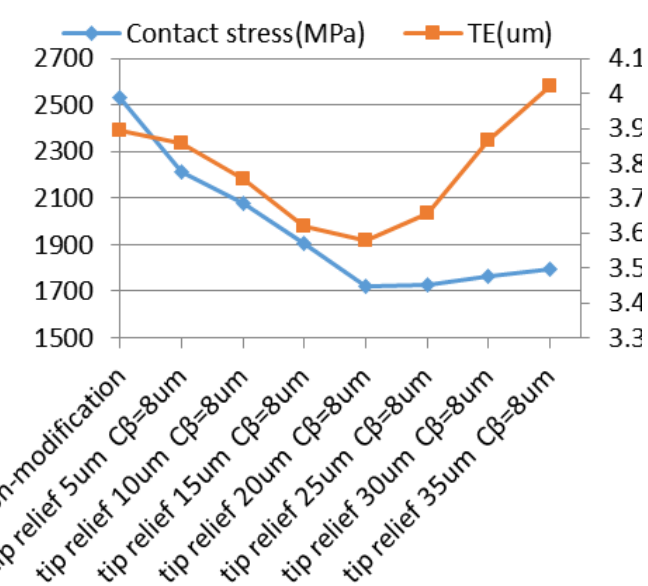

Fig. 9. Contact stress and TE with different micro modifications. 
From Fig. , it is clearly observed that for this gear pair, both of contact stress and TE are minimum when tip relief is 20um (mean mesh deflection) and face crowning is 8um (close to half of manufacturing deviation).

\section{CONCLUSIONS}

For the studied helical gear, from the numerical results presented in above, the following summary can be drawn.

1) The appropriate gear micro modifications can reduce transmission error to get quieter gears.

2) Compare with other micro modifications, tip relief equal to $20 \mathrm{um}$ (mean mesh deflection) and face crowning equal to 8um (close to half of manufacturing deviation) is the optimal. Which means contact stress and TE are minimum when gear micro geometry is defined like this.

3) For other helical gears are likely to show similar trends. Further investigations on other helical gears are planned.

\section{REFERENCES}

[1] M. Henriksson, "Transmission error as gear noise excitation," in Proc. the ASME 2009 International Design Engineering Technical Conferences \& Computers and Information in Engineering Conference, IDETC/CIE 2009, August 30-September 2, 2009, San Diego, California, USA.

[2] ISO 21771:2007, Gears-cylindrical Involute Gears and Gear Pairs-Co ncepts and Geometry.

[3] Y. Jia, "Analysis of gear static transmission error and mesh stiffness," Mechanics and Materials, Trans Tech Publications, Switzerland, vol. 365-366, pp. 327-330, 2013.

[4] Y. A. Tesfahunegn, "The effects of the shape of tooth profile modifications on the transmission error, bending, and contact stress of spur gears," Linear Networks and Systems, Belmont, CA: Wadsworth, pp. 123-135., 1993

[5] P. Velex, "Some analytical results on transmission errors in narrow-faced spur and helical gears: Influence of profile modifications," Journal of Mechanical Design, vol. 133, no. 3, Mar. 2011.

[6] Ulrich Kissling, Effects of Profile Corrections on Peak-to-Peak Transmission Error.

[7] R. C. Frazer, B. A. Shaw, D. Palmer, and M. Fish, "Optimizing gear geometry for minimum transmission error, mesh friction losses and scuffing risk through computer-aided engineering".

[8] H. P. Evans, R. W. Snidle, K. J. Sharif et al., "Analysis of micro-elastohydrodynamic lubrication and prediction of surface fatigue damage in micropitting tests on helical gears," Journal of Tribology, ASME, vol. 135, January 2013,

[9] S. Sundaresan, K. Ishii, and D. R. Houser, "A procedure using manufacturing variance to design gears with minimum transmission error," Journal of Mechanical Design, vol. 113, no. 319, September 1991.

[10] ISO 6336-1:2006, Basic Principle, Introduction and General Influence Factors.
[11] ISO 1328-1:2013, Cylindrical Gears-ISO System of Accuracy. Part 1: Definitions and Allowable Values of Deviations Relevant to Corresponding Flanks of Gear Teeth.

[12] P. Maillardet and D. A. Hofmann, A New Tool for Designing Quiet, Low Vibration Main Propulsion Gears, INEC 96, paper 20, April 1996.

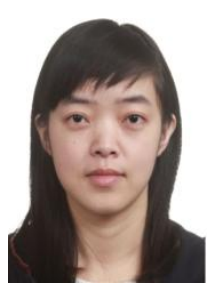

Layue Zhao was born in Hebei province China on $25^{\text {th }}$ December, 1986. She was a graduate of Mechanical Engineering and Automation from Taiyuan University of Science and Technology and went to carry out his master studies at China North Vehicle Research Institute investigating "Dynamic characteristics of planetary gear mechanism". She received her master degree in 2013.

After graduating in 2013, she went on to work for National Key Lab of Vehicular Transmission, China North Vehicle Research Institute based on Beijing, China, where she worked on several transmission projects aimed at reducing vibration and noise of gearbox. She published several articles, including Layue Zhao, etc, "Analysis on the inherent characteristics and dynamic response of gear transmission system", Journal of Vehicle \& Power Technology, 2013.3; Layue Zhao, etc, "Analysis on the steady response of harmonic vibration of the gear system", Manufacturing digital technology conference, 2013.9; Layue Zhao, etc, "Analysis on the dynamic response of hydraulic mechanical integrated transmission device", Manufacturing digital technology conference, 2013.9; Layue Zhao, Robert C Frazer and Brian Shaw, "Comparative study of stress analysis of gears with different helix angle using the ISO 6336 standard and TCA methods", Journal of Mechanical Engineering Science, 2015.

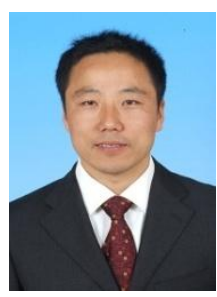

Minggang Du was born in Inner Mongolia, China, on 30th December, 1973. He was a graduate of Vehicle Engineering from Beijing Institute of Technology.

After graduating in 1997, He went on to work for National Key Lab Of Vehicular Transmission, China North Vehicle Research Institute based on Beijing, China, where He worked on several transmission projects overall design. He published several articles, Jinle Zhang, Minggang Du, etc, "Torsional vibration analysis of Fastening structure based on finite element method", ICMA, 2015.8; Jinle Zhang, Minggang Du, etc, "Simulation on loosening behavior of threaded fastener under transverse vibration", ICMA, 2015.8; Minggang $\mathrm{Du}$, etc, "Reliability prediction of the integrated transmission based on interval AHP and safty factor", 2015 4th ICCME, 2015.10.

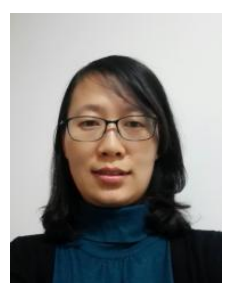

Yang Yang was born in Shaanxi, China on 28th October, 1973. She was a postgraduate of vehicle engineering from Beijing Institute of Technology and received her master degree in 2007. Then She went on to work for National Key Lab of Vehicular Transmission, China North Vehicle Research Institute based on Beijing, China. And she worked mainly on overall design of the transmission projects. 